\title{
Pollution Monitoring using the Leaf-deposited Particulates and Magnetism of the Leaves of 23 Plant Species in a Semi-arid City, Northwest China
}

Hong Chen ( $\square$ chenh34520@163.com )

CDNU: Chengdu Normal University https://orcid.org/0000-0003-2690-9311

Dunsheng Xia

Lanzhou University

Bo Wang

Zhejiang Normal University

Hui Liu

Lanzhou University

Xiaoyi Ma

Lanzhou University

Research Article

Keywords: leaf-deposited particles, magnetic properties, SEM, pollution source, semi-arid area

Posted Date: June 14th, 2021

DOl: https://doi.org/10.21203/rs.3.rs-330666/v1

License: (9) This work is licensed under a Creative Commons Attribution 4.0 International License.

Read Full License 


\section{Abstract}

We conducted a study of the leaf-deposited particles and magnetism of plant leaves in different functional areas (traffic areas, parks and residential areas) in Lanzhou, China. The saturation isothermal remanence (SIRM) of the washed and unwashed leaves of 23 plant species (including evergreen shrubs, deciduous shrubs, deciduous liana species and deciduous trees) at three sampling heights $(0.5 \mathrm{~m}, 1.5 \mathrm{~m}$ and $2.5 \mathrm{~m}$ ) was measured. In addition, the mass of the leaf-deposited particles was measured using the elution-filtration method and the leaf morphological characteristics were determined by scanning electronic microscope (SEM) analysis. The results revealed significant differences in particles retention capacity among the 23 plant species, with evergreen shrub species at the heights of $0.5 \mathrm{~m}$ and $1.5 \mathrm{~m}$ having higher particles concentrations. Buxus sinica, Buxus megistophylla, Prunus cerasifera and Ligustrumxvicaryi were the most effective plant species for accumulating particles. The SEM results showed that leaves with a relatively complex adaxial surface (such as deep grooves and protrusions) were more effective at accumulating particles. The SIRM of washed leaves, unwashed leaves and leafdeposited particles were significantly higher in traffic areas than in parks and residential areas. In addition, significant correlations were found between SIRM of unwashed leaves and leaf-deposited particles and the mass of leaf-deposited particles, and therefore the leaf magnetic properties effectively reflect levels of PM pollution under different environmental conditions. Overall, our results provide a valuable reference for the selection of plant species with high particle retention capacity that suitable for urban greening and pollution mitigation.

\section{Introduction}

Human health and well-being are closely related to the quality of the urban environment. Approximately $55 \%$ of the global population lives in cities and the trend of increasing urbanization and the growth of cities will continue. However, poor urban air quality diminishes people's sense of well-being and increases health risks such as respiratory (Evans et al., 2014) and cardiovascular diseases (Wilker et al., 2013). Consequently, urban development is increasing concerned with building an ecological and pleasant living environment. As one of the most important aspects of such efforts, urban vegetation plays a crucial role in optimizing the urban environment by regulating the microclimate, reducing noise and mitigating particulate matter (PM) pollution (Baldauf, 2017). The benefits of vegetation have been demonstrated studies using model simulations (Gromke and Ruck, 2009; Selmi et al., 2016), wind tunnels (Gromke and Ruck, 2009; Wang et al., 2019) and field experiments (He et al., 2020; Shao et al., 2019; Yan et al., 2019). Urban green infrastructure, such as hedges, both in closed and open-road environments, significantly reduces pollutants such as particulate matter (Al-Dabbous and Kumar, 2014), black carbon (Abhijith and Kumar, 2019), and trace metals (Abhijith and Kumar, 2019). Although several studies have shown that trees in street canyons may cause a deterioration in air quality by reducing ventilation (Morakinyo et al., 2016; Yli-Pelkonen et al., 2017), appropriate urban greening vegetation can overall improve the urban environment. 
Environmental magnetism, especially measurements of saturation isothermal remanent magnetization (SIRM), is widely used for monitoring of PM pollution (Baldacchini et al., 2017; Castanheiro et al., 2016; Chen et al., 2019; Hofman et al., 2016), which is present as leaf-deposited and leaf-encapsulated particles in vegetation (Jouraeva et al., 2002; Popek et al., 2013). However, previous studies have shown that there are significant inter-species differences in the efficiency of PM removal by plant leaves because of differences in vegetation type (Islam et al., 2012) and leaf morphology (Shao et al., 2019; Wang et al., 2013). Therefore, it is necessary to carefully investigate the particle retention capacity of the leaves of common urban greening plants, and to determine whether the particle retention capacity of leaves is consistent with the magnetic characteristics of the leaves of different plant species in different environmental conditions, in order to see which plant species performs best in biomagnetic monitoring.

In addition, external factors, for instance, meteorological factors (Luan et al., 2019; Xu et al., 2017) and the pollution intensity (Przybysz et al., 2014), have been shown to be critical factors affecting the retention of PM on the surface of leaves. In addition, leaf waxes can also incorporate different fractions of PM $(0.2 \sim 100 \mu \mathrm{m})$ (Dzierzanowski et al., 2011). Consequently, the occurrence of PM on or in leaves can be tested by washing with water and chloroform and SIRM measurements of unwashed and washed leaves. The differences in the magnetism of washed and unwashed leaves help to understand the contribution of leaf-deposited particles to the magnetic signal. Such research can potentially help formulate urban greening management policies, such as determining the frequency and composition of green belts.

The specific aims of the present study were as follows: (1) To identify differences in the levels of PM pollution among areas of high traffic density, parks and residential areas in Lanzhou, a major city and transport hub in Northwest China. (2) To explore the differences in particle retention and magnetic contamination of the leaves of different plant species. (3) To evaluate differences in the magnetism of washed and unwashed leaves.

\section{Materials And Methods}

\subsection{Study area}

Lanzhou city is located in Northwest China (Fig. 1), at the convergence zone between the Tibetan Plateau, Inner Mongolia Plateau and the Chinese Loess Plateau. Lanzhou is situated in a basin surrounded by mountains, at an average elevation of 1500 masl. Lanzhou is a typical Chinese city located in the semiarid area with low annual average wind speed $\left(\sim 1.24 \mathrm{~m} \cdot \mathrm{s}^{-1}\right)$ and an annual precipitation of less than 400 $\mathrm{mm}$. Air pollution in urban Lanzhou is mainly characterized by a mixture of suspended dust, soot, volatile organic compounds (VOCs) and motor vehicle exhausts. The annual concentrations of $\mathrm{PM}_{10}$ and $\mathrm{PM}_{2.5}$ exceed the $2^{\text {nd }}$ grade standard of the state, China $\left(70 \mu \mathrm{g} \cdot \mathrm{m}^{-3}\right.$ and $\left.35 \mu \mathrm{g} \cdot \mathrm{m}^{-3}\right)$, and the quantity of dust fall is 12.81 ton $\mathrm{km}^{-2}$ month$^{-1}$ in 2016 (Bureau, 2016). High concentration of heavy metal in dust fall were observed, which were mainly contributed by anthropogenic sources (Li et al., 2020). According to the statistical yearbook of Lanzhou, Lanzhou had a population of $>3$ million inhabitants. The total number 
of civilian cars in the city was 898,800 by the end of 2016 , the road traffic density (total number of motor vehicles/total length of roads) is approximately $750 \mathrm{cars} \cdot \mathrm{km}^{-1}$, causing serious traffic congestion. Traffic pollution has become one of the important factors affecting environmental pollution in Lanzhou.

Moreover, due to the influence of valley topography, the urban inversion layer occurs in approximately $80 \%$ of the year, and when it does, it is long-lasting and sometimes lasts during the whole day, which is not conducive to the diffusion of atmospheric pollutants.

\subsection{Sampling}

In order to compare the PM contamination and magnetic characteristics of the surface of leaves under different environmental conditions, leaf samples were collected from three different functional areas (Fig. 1): (I)traffic areas, where the distance between the sampling sites and main road was less than $5 \mathrm{~m}$. (II) Parks, where samples were collected from the central area that was at least $1 \mathrm{~km}$ far away from the road, to minimize the impact of traffic. (III) Residential areas, hospitals and university campuses, with a high frequency of various human activities and many domestic emissions.

In August 2016, leaf samples from 23 plant species were collected (SI Table 1). They included 1 deciduous liana species, 2 deciduous shrub species, 4 evergreen shrub species all sampled at a height of $0.5 \mathrm{~m}$ above the ground surface, 1 evergreen shrub species, 4 deciduous shrub species, and 3 deciduous tree species all sampled at the height of $1.5 \mathrm{~m}$ above the ground surface, and 8 deciduous tree species sampled at the height of $2.5 \mathrm{~m}$ above the ground surface. The plant species were divided into 7 types depending on plant type [shrubs and trees; deciduous (D) and evergreen (E) species] and the height of sampling above the ground surface: $0.5 \mathrm{~m}$-Lianas-D, $0.5 \mathrm{~m}$-Shrubs-D, $0.5 \mathrm{~m}$-Shrubs-E, $1.5 \mathrm{~m}$-Shrubs-D, 1.5 $\mathrm{m}$-Shrubs-E and $2.5 \mathrm{~m}$-Trees-D. The oldest leaves in the newest twigs were choose, mature and undamaged leaves were collected from the outer canopy. All leaves were sampled from the side facing to the road in traffic areas and any of the sides in residential areas/parks. In order to reduce random error, three subsamples were collected for each species, the number of leaves for each subsample depends on the size of the leaf. The weather conditions during sampling were dry (there was no precipitation during the 15 days preceding sampling) and the air was still and clear. Disposable plastic gloves were used for sampling and they were changed after each sample to avoid cross-contamination. Leaves were tightly packed together using cling film to prevent movement and were then placed in a plastic pot of $8 \mathrm{~cm}^{3}$ volume in the field. All leaf samples were refrigerated at $5{ }^{\circ} \mathrm{C}$ prior to transport to the laboratory. In total, 601 sampling sites were chosen; 4,056 leaves were selected for SIRM and mass of leaf-deposited particles measurement (SI Table 1).

\subsection{Magnetic measurements}

Unwashed and washed (washing procedures were shown in section 1.4) leaf samples were magnetized in a direct current (DC) field of $1 \mathrm{~T}$ with an MM PM10 pulse magnetizer. SIRM was measured with an 
AGICO JR6 magnetometer and the resulting values normalized according to total leaf area [TLA $\left.\left(\mathrm{m}^{2}\right)\right]$. The remanence of unwashed leaves was recorded as $\operatorname{SIRM}_{u}\left(\times 10^{-6} A\right)$, which represents the total remanence (including of leaf-deposited and encapsulated particles, and the leaves themselves). The remanence of washed samples was recorded as $\operatorname{SIRM}_{w}\left(\times 10^{-6} \mathrm{~A}\right)$, which represents the magnetic signal of leaf-encapsulated particles and the leaves themselves. In general, the $\mathrm{SIRM}_{\mathrm{w}}$ of the leaves was negligible. Consequently, the difference SIRM ${ }_{u-w}\left(S_{\text {SIRM }}=\right.$ SIRM $_{u}-$ SIRM $\left._{w}\right)$ between SIRMu and SIRMw is assumed to represent the magnetic signal of leaf-deposited particles (Hofman et al., 2014). The SIRM was measured in the Key Laboratory of Western China's Environmental Systems (Ministry of Education), Lanzhou University, China.

\subsection{Mass of leaf-deposited particles}

The mass of leaf-deposited particles was measured within one day after sampling, by the elutionfiltration method, as follows: after $\mathrm{SIRM}_{u}$ measurement, the leaves were removed from the pots and the cling film that were rinsed to make sure the adhered particles were removed, and then were placed in a beaker with $200 \mathrm{ml}$ of distilled water; they were then washed with a non-depilatory soft brush for $\sim 1 \mathrm{~min}$ to ensure that particles on the surface of the leaves were transferred to the water. And then the beaker was placed into an ultrasonic cleaner (KQ-500DE) for 2-3 min to further ensure that leaf-deposited particles were removed, and the leaves were then carefully removed with tweezers. The suspension was then agitated with the ultrasonic cleaner (KQ-500DE) for 10 to 20 min to make it homogeneous, and then, were sieved using a nylon sieve $(1 \mathrm{~mm})$ to remove large impurities and then were filtered using quartz filters (whatman, filter size: $0.2 \mu \mathrm{m}$ ), and dried and weighed $\left(W_{1}\right)$ using an electronic balance (PT$104 / 35 \mathrm{~S}$, accuracy of $0.01 \mathrm{mg}$ ). The filters with adhering particles were then oven-dried at $80^{\circ} \mathrm{C}$ for $24 \mathrm{~h}$ reweighed $\left(W_{2}\right)$. The mass of the particles deposited on the surface of the leaves was calculated as $W_{2}{ }^{-}$ $W_{1}$.

After the washing, leaves were wiped using a kitchen towel, leaf area $\left[L A\left(\mathrm{~cm}^{2}\right)\right]$ of each leaf was then measured using the following procedure. First, leaves were scanned using a scanner (CanoScan LiDE120) and coordinate paper, and Image $\mathrm{J}$ image processing software (https://imagej.en.softonic.com/) was then used to calculate $L A$. The particle retention capacity was defined as the weight of particles deposited per unit leaf area $\left(\mathrm{g} \cdot \mathrm{m}^{-2}\right)$, which was calculated as:

mass of leaf-deposited particles $=\frac{W_{2}-W_{1}}{T L A}$

where $W_{2}=$ total mass of filter and particles, $W_{1}=$ mass of filter, $T L A=$ total leaf area of each subsample $\left(\mathrm{m}^{2}\right)$ which is the summed area of all individual values of $L A$. 


\subsection{SEM observations of adaxial and abaxial leaf surface morphology}

In order to explore the relationship between the adaxial and abaxial leaf surface characteristics and particle retention capacity of different plant species, leaves were scanned using a field emission scanning electron microscope (SEM) (Apreo S, Thermo Fisher SCIENTIFIC, USA). Two pieces of rounded leaf near the center of the laminae were cut, $0.7 \mathrm{~cm}$ in diameter, and the adaxial surface was marked using a marker. The cut samples were then dried using a vacuum freeze-drier for $48 \mathrm{~h}$ to ensure that the original shape of the stomata on the leaf surfaces was maintained. The samples were then placed on a metal slide with double-sided tape and coated with a layer of gold using a high vacuum sputter coater to increase electrical conductivity and to improve optical transmission. For each sample, the images were scanned at different magnification levels $(\times 250, \times 500, \times 1,000)$.

\subsection{Data analysis}

Kolmogorov-smirnov test was used to verify the normality of data. And then A nonparametric test which does not assume that data follow a specific distribution, was performed to determine whether there were significant differences between the mass of leaf-deposited particles, $\operatorname{SIRM}_{u}, \operatorname{SIRM}_{\mathrm{w}}$, and $\mathrm{SIRM}_{\mathrm{u}-\mathrm{w}}$ within different functional areas (traffic areas, residential areas and parks), life forms (trees, shrubs and lianas) and life habits (evergreen and deciduous). The Kruskal-Wallis one-way ANOVA (k-sample) was used for multiple comparisons. In order to aid the election of plant species with maximum dust retention ability for urban greening management, hierarchical cluster analysis was used to classify plant species, the clustering method is "between-groups linkage", with the mass of leaf-deposited particles as the variable. Data analysis was performed using SPSS (v.22.0, SPSS Inc., Chicago, IL, USA『and Origin (v.2018, OriginLab, USA).

\section{Results}

\subsection{Mass of leaf-deposited particles}

\subsubsection{Mass of leaf-deposited particles for different plant types}

The mass of leaves-deposited particles among different plant types, growth habits and at different heights are compared in Fig. 2 and SI Table 2. There are significant differences between the seven distinguished plant types $(p<0.0001)$. Across all plant types, the mass of particles deposited on the evergreen shrubs ( $0.5 \mathrm{~m}$-Shrubs-E and $1.5 \mathrm{~m}$-Shrubs-E) are significantly higher than for the other plant types $(p<0.05)$, being 2.47 and 2.17 times higher than that for $1.5 \mathrm{~m}$-Trees-D which has the lowest mass. 
In addition, within the evergreen shrubs, the mass of particles of $0.5 \mathrm{~m}$-Shrubs-E is higher than that for 1.5 $m-S h r u b s-E$, but the difference is not statistically significant $(p>0.05)$.

In addition, there are substantial differences in the mass of leaf-deposited particles within the same plant types (Fig. 3). Within plant type $0.5 \mathrm{~m}$-Shrubs-D, the mass for Prunusxcistena is 10 times higher than that for Berberis thunbergii $(\mathrm{p}<0.0001)$. Within the type $0.5 \mathrm{~m}$-Shrubs-E, Buxus sinica had the highest mass of leaf-deposited particles of all 23 plant species examined in the study, with mass much higher than those for the three other species in the plant type $(p<0.05)$. Within this plant type the species can be ordered as follows: Buxus sinica > Buxus megistophylla > Ligustrumxvicaryi $>$ Rosa chinensis. Within plant type 1.5 $\mathrm{m}$-Shrubs-D, the mass of leaf-deposited particles decreases in the sequence of Syzygium aromaticum > Amygdalus triloba > Amygdalus persica > Lonicera maackii, however, there are no significant differences in mass of leaf-deposited particles among the four species. Within plant type $1.5 \mathrm{~m}$-Trees-D, the mass of leaf-deposited particles decreases in the sequence of Malus $\times$ micromalus Makino > Cerasus yedoensis > Sophora japonica f. pendula; however, there were no statistically significant differences in mass of leafdeposited particles among the four plant species $(p>0.05)$. Within the plant type $2.5 \mathrm{~m}$-Trees-D, the mass of leaf-deposited particles decreases in the sequence of Robinia pseudoacacia > Fraxinus chinensis > Ulmus pumila > Sophora japonica > Salix matsudana > Ailanthus altissima > Ginkgo biloba > Salix babylonica. The values for Robinia pseudoacacia, Fraxinus chinensis, Ulmus pumila and Sophora japonica are significantly higher than those for Salix babylonica $(\mathrm{p}<0.05)$, although the differences within the plant types are not statistically significant $(p>0.05)$.

\subsubsection{Mass Of Leaf-deposited Particles Between Different Functional Areas}

The concentration of leaf-deposited particles of each species varies between different functional areas (traffic areas, residential areas and parks) (Fig. 4). Across all plant types, the mass of leaf-deposited particles in traffic areas is higher than in residential areas and parks. However, there are no statistically significant differences between the three areas for $0.5 \mathrm{~m}$-Liana-D, $0.5 \mathrm{~m}$-Shrub-D, $1.5 \mathrm{~m}$-Shrub-E and 1.5 $m$-Tree-D $(p>0.05)$. For the three other plant types, the mass of leaf-deposited particles in traffic areas are significantly higher than those from residential areas and parks $(p<0.0001)$, while there are no significant differences for those from residential areas and parks $(p>0.05)$.

\subsection{Sirm Results}

\subsubsection{Differences in leaf magnetism between different plant types}

The SIRM values of the unwashed leaves $\left(\mathrm{SIRM}_{\mathrm{u}}\right)$ are significantly different $(\mathrm{p}<0.0001)$ among the seven considered plant types, which is similar to the results for the mass of leaf-deposited particles. In detail, 
the SIRM $_{u}$ of the $0.5 \mathrm{~m}$-Shrub-E type is significantly higher $(p<0.0001)$ than that for the other plant types, and the lowest values are in the $1.5 \mathrm{~m}$-Tree-D type (Fig. 5). The SIRM $\mathrm{w}_{\mathrm{w}}$ of $0.5 \mathrm{~m}$-Shrub-E type is significantly higher than $0.5 \mathrm{~m}$-Shrubs-D type $(p<0.0001), 1.5 \mathrm{~m}$-Shrubs-D and $1.5 \mathrm{~m}$-trees-D ( $p<$ 0.05). The variation in the SIRM of leaf-deposited particles $\left(S I_{\mathrm{RM}} \mathrm{M}_{\mathrm{u}}\right)$ among the seven plant types are consistent with the results for $\mathrm{SIRM}_{\mathrm{u}}$. In addition, both $\mathrm{SIRM}_{\mathrm{u}}$ and $\mathrm{SIRM}_{\mathrm{u}-\mathrm{w}}$ are higher for evergreen shrub species at the heights of $0.5 \mathrm{~m}$ and $1.5 \mathrm{~m}(p<0.05)$.

Similar to the particle mass of leaf-deposited particles results, the values of $\operatorname{SIRM}_{u}$, $\operatorname{SIRM}_{u-w}$ and $\operatorname{SIRM}_{w}$ among plant species differ even within the same plant species. In detail, among the 23 plant species, the highest values of $\mathrm{SIRM}_{u}$ and $\mathrm{SIRM}_{\mathrm{u}-\mathrm{w}}$ occur for Buxus sinica and the lowest values for Berberis thunbergii (Fig. 6a, c. Among the seven plant types, there is a near perfect correlation between the $\mathrm{SIRM}_{u}$ and SIRM $_{\mathrm{u}-\mathrm{w}}$ results and mass of leaf-deposited particles (Table 1).

Table 1

Correlations between SIRM ${ }_{\mathrm{u}}$ SIRM $\mathrm{SI}_{\mathrm{u}-\mathrm{w}}$ and the mass of leaf-deposited particles of seven plant types. $\mathrm{S}_{\mathrm{u}}=\mathrm{SIRM}$ of unwashed leaves, $\mathrm{SIRM}_{\mathrm{u}-\mathrm{w}}=$ the difference between $\operatorname{SIRM}_{u}$ and $\operatorname{SIRM}_{w}, M=$ Mass of leaf-deposited particles. $D=$ Deciduous $(n=361), E=$ Evergreen $(\mathrm{n}=240) .{ }^{\mathrm{a}}$ represents $p<0.0001,{ }^{\mathrm{b}}$ represents $p<0.05$.

\begin{tabular}{|lllll|}
\hline Plant types & Regression equation & $\mathbf{r}$ & Regression equation & $\mathbf{r}$ \\
\hline $0.5 \mathrm{~m}$-Liana-D & $\mathrm{S}_{\mathrm{u}}=40.23 \mathrm{M}+42.15$ & $0.91^{\mathrm{a}}$ & $\mathrm{S}_{\mathrm{u}-\mathrm{w}}=33.17 \mathrm{M}+29.62$ & $0.91^{\mathrm{a}}$ \\
\hline $0.5 \mathrm{~m}$-Shrub-D & $\mathrm{S}_{\mathrm{u}}=71.34 \mathrm{M}+27.22$ & $0.89^{a}$ & $\mathrm{~S}_{\mathrm{u}-\mathrm{w}}=57.63 \mathrm{M}+12.54$ & $0.93^{\mathrm{a}}$ \\
\hline $1.5 \mathrm{~m}$-Shrub-D & $\mathrm{S}_{\mathrm{u}}=80.84 \mathrm{M}-2.51$ & $0.92^{a^{a}}$ & $\mathrm{~S}_{\mathrm{u}-\mathrm{w}}=73.21 \mathrm{M}-20.66$ & $0.92^{\mathrm{a}}$ \\
\hline $0.5 \mathrm{~m}$-Shrub-E & $\mathrm{S}_{\mathrm{u}}=68.94 \mathrm{M}+33.34$ & $0.93^{a}$ & $\mathrm{~S}_{\mathrm{u}-\mathrm{w}}=62.62 \mathrm{M}+9.61$ & $0.92^{\mathrm{a}}$ \\
\hline $1.5 \mathrm{~m}$-Shrub-E & $\mathrm{S}_{\mathrm{u}}=78.24 \mathrm{M}+6.94$ & $0.90^{a}$ & $\mathrm{~S}_{\mathrm{u}-\mathrm{w}}=66.36 \mathrm{M}-7.11$ & $0.90^{\mathrm{a}}$ \\
\hline $1.5 \mathrm{~m}$-tree-D & $\mathrm{S}_{\mathrm{u}}=65.87 \mathrm{M}+8.61$ & $0.87^{\mathrm{b}}$ & $\mathrm{S}_{\mathrm{u}-\mathrm{w}}=58.41 \mathrm{M}-6.56$ & $0.92^{\mathrm{a}}$ \\
\hline $2.5 \mathrm{~m}$-tree-D & $\mathrm{S}_{\mathrm{u}}=79.06 \mathrm{M}+25.03$ & $0.69^{a}$ & $\mathrm{~S}_{\mathrm{u}-\mathrm{w}}=57.983 \mathrm{M}+4.78$ & $0.72^{\mathrm{a}}$ \\
\hline
\end{tabular}

\subsubsection{Differences In Leaf Magnetism Between Different Functional Areas}

The variations in $\mathrm{SIRM}_{\mathrm{u}}, \mathrm{SIRM}_{\mathrm{u}-\mathrm{w}}$ and $\mathrm{SIRM}_{\mathrm{w}}$ of each plant type in different functional areas are consistent with the particle weight results. The values for areas of high traffic density are consistently higher than those for residential areas and parks (Fig. 7), and the differences are statistically significant 
$(\mathrm{p}<0.05)$ (SI Table 3), especially for 0.5 m-Shrubs-E, 1.5 m-Shrubs-D, 1.5 m-Trees-D and 2.5 m-Trees-D. However, no statistically significant differences $(p>0.05)$ are observed between parks and residential areas across all plant types (SI Table 4). In addition, the variations of $\mathrm{SIRM}_{\mathrm{u}}, \mathrm{SIRM}_{\mathrm{u}-\mathrm{w}}$ and $\mathrm{SIRM}_{\mathrm{w}}$ are mutually consistent for the seven plant types (Fig. 7).

\subsubsection{Ratios Of Sirm/sirm And Sirm/sirm}

For all plant species, the mean SIRM $_{u-w} / S_{\text {SIRM }}$ ratio is $68 \%$, range from $47 \%-89 \%$. The value varies in plant species, the low values are found for Ailanthus altissima, Salix babylonica, Robinia pseudoacacia, Sophora japonica, Salix matsudana, Ginkgo biloba, Ulmus pumila in plant type $2.5 \mathrm{~m}-T$ ree-D, and Malusxmicromalus Makino, Cerasus yedoensis, Sophora japonica $f$. pendula in plant type 1.5 m Tree-D (SI Fig. 1). The SIRM ${ }_{u-w} / S_{\text {SIRM }}$ values are significant lower $(p<0.0001)$ in parks $(63.60 \%)$ and residential areas $(63.53 \%)$ than in traffic areas $(70.79 \%)$.

\subsection{Correlations between leaf magnetism and the mass of leaf-deposited particles}

Significant correlations were found between the mass of leaf-deposited of particles and SIRM $_{\mathrm{u}}$ and $\operatorname{SIRM}_{\mathrm{u}-\mathrm{w}}(r=0.79 \sim 0.91)$ in parks, residential areas and traffic areas, as shown in Table 2, with stronger correlations between the mass of leaf-deposited particles and SIRM $_{u-w}$ than for SIRM $_{u}$. In addition, for SIRM $_{\mathrm{u}-\mathrm{w}}$, the correlation coefficient for traffic areas $(r=0.91)$ is higher than for residential areas $(r=0.87)$ and parks $(r=0.87)$. Nonsignificant correlations were found between the mass of leaf-deposited particles and $\operatorname{SIRM}_{W}(r=0.18 \sim 0.43)$; however, finite SIRM $_{W}$ values can still be observed for washed leaves.

Table 2

Correlations between SIRM $_{u}$, SIRM $_{w}$, SIRM $_{u-w}$ and the mass of leaf-deposited particles from traffic areas, residential areas and parks. SIRM $=$ SIRM of unwashed plant leaves, SIRM $_{\mathrm{w}}=$ SIRM of washed plant leaves, SIRM $_{\mathrm{u}-\mathrm{w}}=$ the difference between $\operatorname{SIRM}_{\mathrm{u}}$ and $\mathrm{SIRM}_{\mathrm{w}} \cdot \mathrm{S}=\mathrm{SIRM}, \mathrm{M}=$ Mass of leaf-deposited particles. ${ }^{a}$ represents $\mathrm{p}<0.0001,{ }^{\mathrm{b}}$ represents $p>0.05$.

\begin{tabular}{|c|c|c|c|c|c|c|}
\hline \multirow{2}{*}{$\begin{array}{l}\text { Functional } \\
\text { areas }\end{array}$} & \multicolumn{2}{|l|}{$\operatorname{SIRM}_{u}$} & \multicolumn{2}{|l|}{$\operatorname{SIRM}_{w}$} & \multicolumn{2}{|l|}{$\operatorname{SIRM}_{\mathrm{u}-\mathrm{w}}$} \\
\hline & $\begin{array}{l}\text { Regression } \\
\text { equation }\end{array}$ & $r$ & $\begin{array}{l}\text { Regression } \\
\text { equation }\end{array}$ & $\mathbf{r}$ & $\begin{array}{l}\text { Regression } \\
\text { equation }\end{array}$ & $r$ \\
\hline Traffic areas & $\begin{array}{l}S=62.19 \mathrm{M}+ \\
66.85\end{array}$ & $0.84^{\mathrm{a}}$ & $\begin{array}{l}S=3.74 M+ \\
43.02\end{array}$ & $0.18^{b}$ & $\begin{array}{l}S=58.45 \mathrm{M} \\
+24.82\end{array}$ & $0.91^{\mathrm{a}}$ \\
\hline $\begin{array}{l}\text { Residential } \\
\text { areas }\end{array}$ & $\begin{array}{l}S=44.49 \mathrm{M}+ \\
28.70\end{array}$ & $0.79^{a}$ & $\begin{array}{l}S=6.25 \mathrm{M}+ \\
19.76\end{array}$ & $0.23^{b}$ & $\begin{array}{l}S=38.24 \mathrm{M} \\
+8.94\end{array}$ & $0.87^{a}$ \\
\hline Parks & $\begin{array}{l}S=15.89 \mathrm{M}+ \\
60.30\end{array}$ & $0.84^{a}$ & $\begin{array}{l}S=13.60 \mathrm{M}+ \\
12.84\end{array}$ & $0.43^{b}$ & $\begin{array}{l}S=46.70 \mathrm{M} \\
+3.05\end{array}$ & $0.87^{a}$ \\
\hline
\end{tabular}




\subsection{Leaf Surface Morphology And Distribution Of Particles}

The average concentration of particles of $0.5 \mathrm{~m}$-Shrubs-E is greater than that of $1.5 \mathrm{~m}-\mathrm{Shrubs}-\mathrm{E}$; however, this is not the case for every species within the plant species, which may be caused by differences in leaf morphological characteristics. Buxus sinica at the height of $0.5 \mathrm{~m}$ has the highest particle retention capacity (SI Fig. 2a). The abaxial surface of this species has protrusive stomata with a large opening and deep surrounding grooves where particles are captured. In addition, particles were also observed in the folds between stomata (SI Fig. 2b). For Buxus megistophylla, the particles are heterogeneously existed on both adaxial and abaxial surfaces (SI Fig. 2c, 2d). The area around the stomata comprise a sink area on the abaxial surface where particles cluster together and agglomerations are also found (SI Fig. 2d). The structure of the abaxial surface of Ligustrumxvicaryi is complex because of dense protruding strips where sporadic fine particles were found (SI Fig. 2f). For Rosa chinensis, the adaxial and abaxial surfaces are relatively smooth, where only a few small particles were observed on the adaxial surface (SI Fig. $2 \mathrm{~g}$ ), and large particles (with a diameter about $20 \mu \mathrm{m}$ ) were sporadically scattered around the stomata (SI Fig. 2h). Many particles were observed in the dense, deep stripe-like grooves both on adaxial and abaxial surfaces of Prunus cerasifera (SI Fig. 3a, b); however, particles were largely absent from the areas in between the stomata.

Four deciduous plant species, those at the heights of $0.5 \mathrm{~m}$ to $1.5 \mathrm{~m}$ had a slightly greater particle retention capacity: e.g. the liana species Parthenocissus quinquefolia at $0.5 \mathrm{~m}$, the adaxial surface of which has numerous large particles and deep stripe-like grooves where a lot of particles were observed (SI Fig. 4a, b), and the shrub species Prunus $\times$ cistena at the height of $0.5 \mathrm{~m}$ with a pubescent adaxial surface where particles were observed (SI Fig. 5a). The adaxial surfaces of the shrub species Amygdalus triloba and Syzygium aromaticum at the height of $1.5 \mathrm{~m}$ have protrusions with deep recesses, where large and fine particles were observed (SI Fig. 6a-d); however, the protrusions in Syzygium aromaticum are relatively smooth and only a few particles were observed (SI Fig. 3c). As is evident from SI Fig. 5 and SI Fig. 6 , although stomata, folds, protrusions, and tiny grooves are also present on the abaxial surfaces of the abovementioned seven species of deciduous plants, few particles were found on the surfaces.

In the case of deciduous tree species (1.5 m-Trees-D and $2.5 \mathrm{~m}$-Trees-D) (SI Fig. 7-9), the particles are also trapped on surfaces (SI Fig. 9c) and the cavity left by the breaking of the leaf tissue.

\subsection{Comparison of dust retention capacity of different plant species}

There were significant differences in the mass of leaf-deposited particles of the 23 plant species analyzed in this in this study $(p<0.0001)$. For example, the mass of leaf-deposited particles Buxus sinica, with the highest mass, was 31.7 times higher than that for Berberis thunbergii which had the lowest weight $(p<0.0001)$. The results of hierarchical cluster analysis (Fig. 8a) show that final cluster members were divided into four clusters, with the dust retention capacity decreasing in the following sequence: $\nabla$

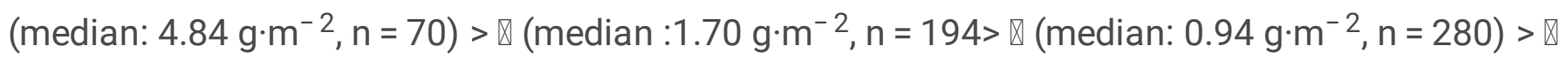
(median: $\left.0.38 \mathrm{~g} \cdot \mathrm{m}^{-2}, \mathrm{n}=57\right)(p<0.0001)$ (Fig. 8b). 


\section{Discussion}

\subsection{Differences in leaf-deposited particles between plant species}

The results indicate significant differences in particle retention capacity among the studied plant species, which relate to differences in life form and growth habits. As shown in Fig. 3, the mass of leaf-deposited particles of the evergreen plant species, except for Rosa chinensis, are higher than for deciduous plant species at the heights of both $0.5 \mathrm{~m}$ (Prunusxcistena and Berberis thunbergii) and $1.5 \mathrm{~m}$ (Amygdalus persica, Syzygium aromaticum, Lonicera maackii and Amygdalus triloba), indicating evergreen plant species have higher dust retention capacity than deciduous at both heights in present study. Consequently, those evergreen plant species with high dust retention capacity are good choices for intercepting particles from the road and mitigating the air pollution at the shorter layer of green infrastructure. Simultaneously, other researchers have also noted that evergreen plants have a higher particle retention capacity than deciduous plants, because of their longer exposure times (Lehndorff et al., 2006) in winter time when the leaves of deciduous plants are absent.

In addition to the difference between evergreen and deciduous trees it is notable that the mass of leafdeposited particles for most of the shrub species were higher than those of trees. This phenomenon has been interpreted as a result of height where the leaves are collected, in urban environments particle density is higher than at larger heights, so these shrubs are exposed to higher concentrations. The effects of height can also be between (Dzierzanowski et al., 2011) found that lower-growing shrubs such as Spiraea japonica had a greater ability to capture PM than trees, based on a survey of eight plant species. It is possible that lower-growing plants are more susceptible to trapping particles derived from splashed soil than is the case for trees (Sæbø et al., 2012). For Hedera helix, collected from different heights on a living wall in Hanover, there was a high degree of variability of the same sizes of PM on leaf surfaces (He et al., 2020). Large PM (diameter $>10 \mu \mathrm{m}$ ) decreased substantially with increasing height, from $0.5 \mathrm{~m}$ to over $2 \mathrm{~m}$; however, for coarse $(2.5-10 \mu \mathrm{m})$ and fine particles $(1-2.5 \mu \mathrm{m})$, the variations were slight. In addition, the effect of sampling height on roadside plant species was reported among different plant species in different areas. For example, (Hofman et al., 2013) found the SIRM of the leaves of Platanusxacerifolia decreased with increasing sampling height in a street canyon in Ghent (Belgium). (Chen et al., 2019) found that more particles were retained by the leaves of Juniperus formosana below the height of $3.4 \mathrm{~m}$ than above that height in an open road environment in Lanzhou, and the SIRM of leafdeposited particles was lower at the heights of 3.6-5.4 m than below $3.4 \mathrm{~m}$, possibly because the leaves at lower position are more influenced by dust suspension caused by vehicle traffic or other human activities. In addition, large particles are less likely to be transported sufficiently high above the ground surface to be deposited on leaves. However, in another study no significant differences were observed in the particles amount at the heights of $0.25 \mathrm{~m}, 1.5 \mathrm{~m}$, and $2.5 \mathrm{~m}$ for Hedera helix on living walls near a traffic road in the Netherland (Ottelé et al., 2010). 
In addition to the foregoing reasons, leaf characteristics are also an important factor affecting the quantity of leaf-deposited particles on different plant species. In this study, the characteristics of the adaxial and abaxial leaf surfaces, and the distribution of particles on these surfaces were observed by SEM. These results indicated that evergreen leaves with more complex structures and rougher surfaces capture more particles, which was also found in the common garden experiment of (Muhammad et al., 2019) on 96 tree, shrub and climber species. As shown in SI Fig. 1-8, for all plant species, leaves with dense protrusions or deep recesses in the protrusions and with stripe-like deep grooves appear to be more efficient at accumulating particles than leaves with simpler surface characteristics. The deep grooves between the protruding guard cells and blades result in a rough surface which promotes particle retention. There was no evidence of a relationship $(r=0.08, p=0.71)$ between stomatal density and particle retention capacity for 23 plant species in this study, similar to the results of (Muhammad et al., 2019; Shao et al., 2019). The reasons why this has not been tested more widely is that not all tree species retain large amounts of PM on the abaxial surface of leaves-where stomata are for most species present and the leaf surface structure of different tree species is significantly different, making it difficult to determine the major factor(s) influencing particle retention capacity.

For all plant species in the present study no relationship $(p>0.05)$ between leaf area and the mass of leaf-deposited particles (and magnetic properties) was observed, which was also the case in the study of (Sæbø et al., 2012).

Across all of the plant species, SIRM $_{\mathrm{w}}$ contributed $\sim 11-54 \%$ of $\mathrm{SIRM}_{\mathrm{u}}$, which indicates that magnetic particles are also captured by leaf wax, the results are in line with the research of (Hofman et al., 2014), who revealed that particles contribute $38 \%$ of the leaf SIRM signal. (Muhammad et al., 2020) also indicated that washed leaf SIRM can be a good indicator to determine the effectiveness of a plant species in particles immobilization on a survey of 96 plant species in Antwerp, Belgium. In general, the waxy layer promotes the accumulation of particles (Burkhardt, 2010; Jouraeva et al., 2002; Kaupp et al., 2002; Sabin et al., 2006), but leaf surface with waxes showed degradation, such as natural aging and weathering. Those changes of structure relating to waxes influence the deposition of particles onto leaf surface (Neinhuis and Barthlott, 1998; Watanabe, 2015). However, the amount of PM deposited on the leaf surface and trapped within the waxy layer is debated. For instance, (Xu et al., 2018) reported that the proportions of particles deposited on the leaf surface and in the wax of 17 species in Beijing were $65 \%$ and 35\% PM, respectively. The results of (Sæbø et al., 2012) showed that these proportions differed significantly between species: e.g. Betula pendula accumulated $82.6 \%$ of PM in the wax, while the respective values for Fagus sylvatica and Stephanandra incisa were $25 \%$ and $28 \%$, which were the most effective species in terms of PM deposition. With regard to the size of trapped particles, epicuticular wax may be more effective in capturing fine PM (1-2.5 $\mu \mathrm{m}$ ) (He et al., 2020; Viecco et al., 2018), and (He et al., 2020 ) reported that almost $65 \%$ of the PM in leaf wax consisted of fine PM (1-2.5 $\mu \mathrm{m})$. Above results show that the capture effect of wax on PM is interspecific dependence that might be caused by wax structure which has influence on the leaf wettability that relate to the deposition of particles on the leaf surface (Muhammad et al., 2020). 
According to the SEM results, for the most of plant species, particles are captured on the adaxial surfaces with more complex structures, such as deep stripe-like grooves, protrusions, and the cavity left by the breaking of leaf tissue, and consequently high stomatal density, which mainly occurs on the abaxial surfaces, may not be a decisive factor.. For a few of plant species, e.g. Buxus sinica, Buxus megistophylla and Prunus Cerasifera, particles also can be found on the abaxial surfaces. In conclusion, leaf characteristic is a comprehensive factor that has influence on the deposition of particles, researches indicated that leaf size (Weerakkody et al., 2018; Zhang et al., 1997), wax (Jouraeva et al., 2002; Muhammad et al., 2019), drop contact angle (Muhammad et al., 2019; Wang et al., 2013), hair (Sæbø et al., 2012; Muhammad et al., 2019), can affect particle retention capacity.

\subsection{Influence of pollution sources on the leaf-deposited particles and leaf magnetism}

Significant differences in the mass of leaf-deposited particles and leaf magnetism in different functional areas were found. The concentration of magnetic minerals was mainly determined by the environmental conditions where the plant was located, and that more magnetic minerals were present within and on leaves in traffic areas than in residential areas and parks. By comparing the magnetic characteristics of unwashed leaves, leaf-deposited particles and washed leaves in the traffic areas with those in parks and residential areas, it was found that the variations in amount of magnetic material retained on the surface and inside of the leaves was significantly related to the intensity of human activities, especially road traffic. Previous researches indicated that magnetism of leaf near the road was affected by magnetic particles produced by both vehicular fuel combustion (Harrison et al., 1997) and the abrasion of vehicle brakes and tires (Pant and Harrison, 2013), which were generally considered to be important sources of $\mathrm{PM}$ pollution in urban area. Traffic-related PM usually contains abundant trace metals (e.g., $\mathrm{Pb}, \mathrm{Zn}, \mathrm{Cu}$ ) that are associated with Fe-particles (Baldacchini et al., 2017), which contribute to the leaf magnetism.

Since the sampling points in parks and residential areas are relatively distant from roads $(>1 \mathrm{~km})$, the mass of leaf-deposited particles in these areas was only 40\% of that in traffic areas; in addition, the values of SIRM $_{u}$, SIRM $_{u-w}$ and SIRM ${ }_{w}$ were also lower than in the traffic areas (Fig. 7) .And the more significant correlations between the mass of leaf-deposited particles and $\mathrm{SIRM}_{\mathrm{u}}, \mathrm{SIRM}_{\mathrm{u}-\mathrm{w}}$ in traffic areas $(r=0.84$ and 0.91 , respectively, $p<0.0001)$ than those in parks $(r=0.84$ and 0.87 , respectively, $p<0.0001)$ and residential areas $(r=0.79$ and 0.87 , respectively, $p<0.0001)$ (Table ) were observed in the present study.. The results indicate that leaves collected from different functional areas are both affected by the differences in local sources of atmospheric PM pollution and the distance to the pollution sources. The results were in line with previous studies, for instance, increased amounts of magnetic particles were found to be deposited on the leaves of roadside birch trees (Hofman et al., 2017; Maher et al., 2013). In addition, clear evidence has been found that pollutants from road traffic decrease with increasing distance from the road (Kardel et al., 2012; Zhang et al., 2006).

\subsection{Evaluation of the applicability of biomagnetism monitoring in arid and semi-arid areas}


The occurrence of atmospheric pollution on the leaf surfaces was confirmed by the $\operatorname{SIRM}_{u}$ and $\operatorname{SIRM}_{u-w}$ values, as illustrated in Fig .9. The correlations between the mass of leaf-deposited particles and SIRM $_{u}$ and SIRM $_{\mathrm{u}-\mathrm{w}}$ values decrease in the following sequence, with the correlation coefficients in parentheses: $\mathbb{V}$ $>\mathbb{V}=\mathbb{\nabla}>\mathbb{Q}$. These results indicate that both $\mathrm{SIRM}_{\mathrm{u}}$ and $\mathrm{SIRM}_{\mathrm{u}-\mathrm{w}}$ are good tools for PM monitoring, which have also been demonstrated in previous studies (Hofman et al., 2017); however, the effectiveness of the method varies between different plants. The results of this study have demonstrated that plant species with a higher particle retention capacity are more suitable for monitoring particulate pollution; however, these plant species with great particle trapping capacity are mainly the shorter species which are potentially more vulnerable to road-traffic-derived pollutants which may result in leaf damage (VinitDunand et al., 2002), for example by inhibiting photosynthesis and growth and causing leaf senescence and stomatal damage, and more works should be done about which plant species suit for being planted in the highly polluted areas or which plant species can be used as indicators for degree of urban air pollution (Du et al., 2007). Therefore, the results provide a useful reference for urban greening management. From the point of view of mitigating particulate pollution, plant species Buxus sinica, Buxus megistophylla, Prunusxcistena, Prunus Cerasifera, Ligustrumxvicaryi and Robinia pseudoacacia are good choices in arid and semiarid urban like Lanzhou, which is heavily polluted by PM. Simultaneously, urban greening managers should program the frequency of cleaning these roadside plants reasonably to restore their dust retention ability and reduce the damage of leaf surface particles to leaves.

\section{Conclusions}

We have characterized the particle retention capacity and degree of magnetic contamination of 23 plant species (lianas, shrubs and trees) in areas of varying land use in Lanzhou city. In urban environment, the mass of leaf-deposited particles and leaf magnetism are higher in traffic areas than those in parks and residential areas, indicating that pollution sources had significant influence on leaf-deposited particles. The leaves of evergreen shrub species at heights of $0.5 \mathrm{~m}$ and $1.5 \mathrm{~m}$ above the ground were found to have the greatest particle retention capacity. Leaves with relatively complex surfaces with features such as deep grooves and protrusions had a significantly higher particle retention capacity. The amount of particles retained by the leaves is the sum of the particles on the adaxial and abaxial surfaces; however, for most of the plant species the rough adaxial surfaces are the main area of accumulation of particles, and consequently high stomatal density, which mainly occurs on the abaxial surfaces, may not be a decisive factor. Significant differences in the magnetic contamination of washed and unwashed leaves were observed, indicating that the cleaning process can effectively remove parts of particles deposited on the leaf surfaces. Significant correlations were found between the mass of particles deposited on leaves and SIRM $_{\mathrm{u}-\mathrm{w}}$ for plant species with different particle retention capacities, indicating that such species with high dust retention capacity are more suitable for biomagnetic monitoring, e.g. from the point of view of mitigating particulate pollution, those plant species, for instance, Buxus sinica, Buxus megistophylla, Prunusxcistena, Prunus Cerasifera, Ligustrumxvicaryi and Robinia pseudoacacia are good choices for urban greening vegetation inarid and semiarid urban in all the considered species, because of 
their high dust retention capacity. In addition, in order to improve air quality, different combinations of plant types (trees, shrubs, climbers and herbs) should be explored, together with aesthetics aspects, in order to formulate an optimum planting and urban management policy in Lanzhou.

\section{Declarations}

\section{Acknowledgements}

We appreciate Dr. Jan Bloemendal in University of Liverpool and Prof. Roeland Samson in Antwerp University for critical discussions, constructive suggestion and English improvement.

\section{Authors Contributions}

Hong Chen: Conceptualization, Validation, Formal analysis, Investigation, Resources, Writing-Original Draft.

Dun-sheng Xia: Conceptualization, Funding acquisition, Writing-Review \& Editing.

Bo Wang*: Conceptualization, Funding acquisition, Investigation, Resources.

Hui Liu: Writing-Review \& Editing

Xiaoyi Ma: Writing-Review \& Editing

\section{Funding}

This work was supported by the National Natural Science Foundation of China (grants 41877444 and 41504056), General Project of Zhejiang Natural Science Foundation, China (LY20D040001), and China Scholarship Council under file number 201906180080.

Data availability Not applicable

Conflict of interest The author declares that she has no conflict of interest.

Ethics approval and consent to participate Not applicable.

Consent for publication Not applicable.

\section{References}

1. Abhijith KV, Kumar P. 2019. Field investigations for evaluating green infrastructure effects on air quality in open-road conditions. Atmospheric Environment. 201: 132-147.

2. Al-Dabbous AN, Kumar P. 2014. The influence of roadside vegetation barriers on airborne nanoparticles and pedestrians exposure under varying wind conditions. Atmospheric Environment. 90: 113-124.

3. Baldacchini C, Castanheiro A, Maghakyan N, Sgrigna G, Verhelst J, Alonso R, Amorim JH, Bellan P, Bojovic DD, Breuste J, Buhler O, Cantar IC, Carinanos P, Carriero G, Churkina G, Dinca L, Esposito R, 
Gawronski SW, Kern M, Le Thiec D, Moretti M, Ningal T, Rantzoudi EC, Sinjur I, Stojanova B, Anicic Urosevic M, Velikova V, Zivojinovic I, Sahakyan L, Calfapietra C, Samson R. 2017. How Does the Amount and Composition of PM Deposited on Platanus acerifolia Leaves Change Across Different Cities in Europe? Environ Sci Technol. 51: 1147-1156.

4. Baldauf R. 2017. Roadside vegetation design characteristics that can improve local, near-road air quality. Transportation Research Part D: Transport and Environment. 52: 354-361.

5. Lanzhou Mubicipal Environmental Protection Bureau. 2016. Environmental air quality monitoring report of lanzhou city in 2016, http://hbj.lanzhou.gov.cn/col/col5964/index.html? uid=19629\&pageNum=6.

6. Burkhardt J. 2010. Hygroscopic particles on leaves: nutrients or desiccants? Ecological Monographs. 80: 369-399.

7. Castanheiro A, Samson R, De Wael K. 2016. Magnetic- and particle-based techniques to investigate metal deposition on urban green. Sci Total Environ. 571: 594-602.

8. Chen H, Wang B, Xia DS, Fan YJ, Liu H, Tang ZR, Ma S. 2019. The influence of roadside trees on the diffusion of road traffic pollutants and their magnetic characteristics in a typical semi-arid urban area of Northwest China. Environmental Pollution. 252: 1170-1179. DOI:

10.1016/j.envpol.2019.06.023.

9. Du M, Zhang N, Li Y, Hu L, Qiao PJEMC. 2007. Effect of atmosphere pollution on chlorophyll content in greening plant leaves. 23: 86-88 (In Chinese with Englisg abstract).

10. Dzierzanowski K, Popek R, Gawronska H, Saebo A, Gawronski SW. 2011. Deposition of particulate matter of different size fractions on leaf surfaces and in waxes of urban forest species. Int $J$ Phytoremediation. 13: 1037-1046.

11. Evans KA, Halterman JS, Hopke PK, Fagnano M, Rich DQ. 2014. Increased ultrafine particles and carbon monoxide concentrations are associated with asthma exacerbation among urban children. Environ Res. 129: 11-19.

12. Gromke C, Ruck B. 2009. Effects of trees on the dilution of vehicle exhaust emissions in urban street canyons. International Journal of Environment \& Waste Management. 4: 225-242.

13. Harrison RM, Deacon AR, Jones MR, Appleby RS. 1997. Sources and processes affecting concentrations of PM10 and PM2.5 particulate matter in Birmingham (U.K.). Atmospheric Environment. 31: 4103-4117.

14. He C, Qiu K, Pott R. 2020. Reduction of traffic-related particulate matter by roadside plants: effect of traffic pressure and sampling height. Int J Phytoremediation. 22: 184-200.

15. Hofman J, Bartholomeus H, Janssen S, Calders K, Wuyts K, Wittenberghe SV, Samson R. 2016. Influence of tree crown characteristics on the local PM 10 distribution inside an urban street canyon in Antwerp (Belgium): A model and experimental approach. Urban Forestry \& Urban Greening. 20: 265-276.

16. Hofman J, Maher BA, Muxworthy AR, Wuyts K, Castanheiro A, Samson R. 2017. Biomagnetic Monitoring of Atmospheric Pollution: A Review of Magnetic Signatures from Biological Sensors. 
Environ Sci Technol. 51: 6648-6664.

17. Hofman J, Stokkaer I, Snauwaert L, Samson R. 2013. Spatial distribution assessment of particulate matter in an urban street canyon using biomagnetic leaf monitoring of tree crown deposited particles. Environ Pollut. 183: 123-132.

18. Hofman J, Wuyts K, Van Wittenberghe S, Brackx M, Samson R. 2014. On the link between biomagnetic monitoring and leaf-deposited dust load of urban trees: relationships and spatial variability of different particle size fractions. Environ Pollut. 189: 63-72.

19. Islam MN, Rahman K-S, Bahar MM, Habib MA, Ando K, Hattori N. 2012. Pollution attenuation by roadside greenbelt in and around urban areas. Urban Forestry \& Urban Greening. 11: 460-464.

20. Jouraeva VA, Johnson DL, Hassett JP, Nowak DJ. 2002. Differences in accumulation of PAHs and metals on the leaves of Tilia x euchlora and Pyrus calleryana. Environmental Pollution. 120: 331-338.

21. Kardel F, Wuyts K, Maher BA, Samson R. 2012. Intra-urban spatial variation of magnetic particles: Monitoring via leaf saturation isothermal remanent magnetisation (SIRM). Atmospheric Environment. 55: 111-120.

22. Kaupp H, Blumenstock M, Mclachlan MS. 2002. Retention and mobility of atmospheric particleassociated organic pollutant PCDD/Fs and PAHs in maize leaves. New Phytologist. 148: 473-480.

23. Lehndorff E, Urbat M, Schwark L. 2006. Accumulation histories of magnetic particles on pine needles as function of air quality. Atmospheric Environment. 40: 7082-7096.

24. Li Y, Zhao B, Duan K, Cai J, Niu W, Dong X. 2020. Assessments of Water-Soluble Inorganic Ions and Heavy Metals in Atmospheric Dustfall and Topsoil in Lanzhou, China. Int J Environ Res Public Health. 17.

25. Luan T, Guo X, Zhang T, Guo L. 2019. Below-Cloud Aerosol Scavenging by Different-Intensity Rains in Beijing City. Journal of Meteorological Research. 33: 126-137.

26. Maher BA, Ahmed IA, Davison B, Karloukovski V, Clarke R. 2013. Impact of roadside tree lines on indoor concentrations of traffic-derived particulate matter. Environ Sci Technol. 47: 13737-13744.

27. Morakinyo TE, Lam YF, Hao S. 2016. Evaluating the role of green infrastructures on near-road pollutant dispersion and removal: Modelling and measurement. J Environ Manage. 182: 595-605.

28. Muhammad S, Wuyts K, Samson R. 2019. Atmospheric net particle accumulation on 96 plant species with contrasting morphological and anatomical leaf characteristics in a common garden experiment. Atmospheric Environment. 202: 328-344.

29. Muhammad S, Wuyts K, Samson R. 2020. Immobilized atmospheric particulate matter on leaves of 96 urban plant species. Environ Sci Pollut Res Int.

30. Neinhuis C, Barthlott W. 1998. Seasonal changes of leaf surface contamination in beech, oak, and ginkgo in relation to leaf micromorphology and wettability. New Phytologist. 138: 91-98.

31. Ottelé M, van Bohemen HD, Fraaij ALA. 2010. Quantifying the deposition of particulate matter on climber vegetation on living walls. Ecological Engineering. 36: 154-162. 
32. Pant P, Harrison RM. 2013. Estimation of the contribution of road traffic emissions to particulate matter concentrations from field measurements: A review. Atmospheric Environment. 77: 78-97.

33. Popek R, Gawronska H, Wrochna M, Gawronski SW, Sæbø A. 2013. Particulate matter on foliage of 13 woody species: deposition on surfaces and phytostabilisation in waxes-a 3-year study. Int $\mathrm{J}$ Phytoremediation. 15: 245-256.

34. Przybysz A, Saebo A, Hanslin HM, Gawronski SW. 2014. Accumulation of particulate matter and trace elements on vegetation as affected by pollution level, rainfall and the passage of time. Sci Total Environ. 481: 360-369.

35. Sabin L, Heelim J, Teresavenezia M, Winer A, Schiff K, Stolzenbach K. 2006. Dry deposition and resuspension of particle-associated metals near a freeway in Los Angeles. Atmospheric Environment. 40: 7528-7538.

36. Sæb $\varnothing$ A, Popek R, Nawrot B, Hanslin HM, Gawronska H, Gawronski SW. 2012. Plant species differences in particulate matter accumulation on leaf surfaces. Sci Total Environ. 427-428: 347-354.

37. Selmi W, Weber C, Rivière E, Blond N, Mehdi L, Nowak D. 2016. Air pollution removal by trees in public green spaces in Strasbourg city, France. Urban Forestry \& Urban Greening. 17: 192-201.

38. Shao F, Wang L, Sun F, Li G, Yu L, Wang Y, Zeng X, Yan H, Dong L, Bao Z. 2019. Study on different particulate matter retention capacities of the leaf surfaces of eight common garden plants in Hangzhou, China. Sci Total Environ. 652: 939-951.

39. Viecco M, Vera S, Jorquera H, Bustamante W, Gironás J, Dobbs C, Leiva E. 2018. Potential of particle matter dry deposition on green roofs and living walls vegetation for mitigating urban atmospheric pollution in semiarid climates. Sustainability. Sustainability. 10: 2431.

40. Vinit-Dunand F, Epron D, Alaoui-Sossé B. 2002. Effects of copper on growth and on photosynthesis of mature and expanding leaves in cucumber plants. Plant Science (Shannon). 163: 0-58.

41. Wang H, Shi H, Li Y, Yu Y, Zhang J. 2013. Seasonal variations in leaf capturing of particulate matter, surface wettability and micromorphology in urban tree species. Frontiers of Environmental Science \& Engineering. 7: 579-588.

42. Wang HX, Maher BA, Ahmed IA, Davison B. 2019. Efficient Removal of Ultrafine Particles from Diesel Exhaust by Selected Tree Species: Implications for Roadside Planting for Improving the Quality of Urban Air. Environ Sci Technol. 53: 6906-6916.

43. Watanabe Y. 2015. Canopy, leaf surface structure and tree phenology: Arboreal factors influencing aerosol deposition in forests. Journal of Agricultural Meteorology. 71: 167-173.

44. Wilker EH, Mostofsky E, Lue SH, Gold D, Schwartz J, Wellenius GA, Mittleman MA. 2013. Residential proximity to high-traffic roadways and poststroke mortality. J Stroke Cerebrovasc Dis. 22: e366-e372.

45. Xu XW, Zhang ZM, Bao L, Mo L, Yu XX, Fan DX, Lun XX. 2017. Influence of rainfall duration and intensity on particulate matter removal from plant leaves. Sci Total Environ. 609: 11-16.

46. Xu Y, Xu W, Mo L, Heal MR, Xu X, Yu X. 2018. Quantifying particulate matter accumulated on leaves by 17 species of urban trees in Beijing, China. Environ Sci Pollut Res Int. 25: 12545-12556. 
47. Yan G, Yu Z, Wu Y, Liu J, Wang Y, Zhai J, Cong L, Zhang Z. 2019. Understanding PM2.5 concentration and removal efficiency variation in urban forest park-Observation at human breathing height. PeerJ Preprints. 7:e27846v1.

48. Yli-Pelkonen V, Viippola V, Kotze DJ, Setälä H. 2017. Greenbelts do not reduce NO 2 concentrations in near-road environments. Urban Climate. 21: 306-317.

49. Zhang C, Huang B, Li Z, Liu H. 2006. Magnetic properties of high-road-side pine tree leaves in Beijing and their environmental significance. Chinese Science bulletin. 51: 3041-3052.

\section{Figures}

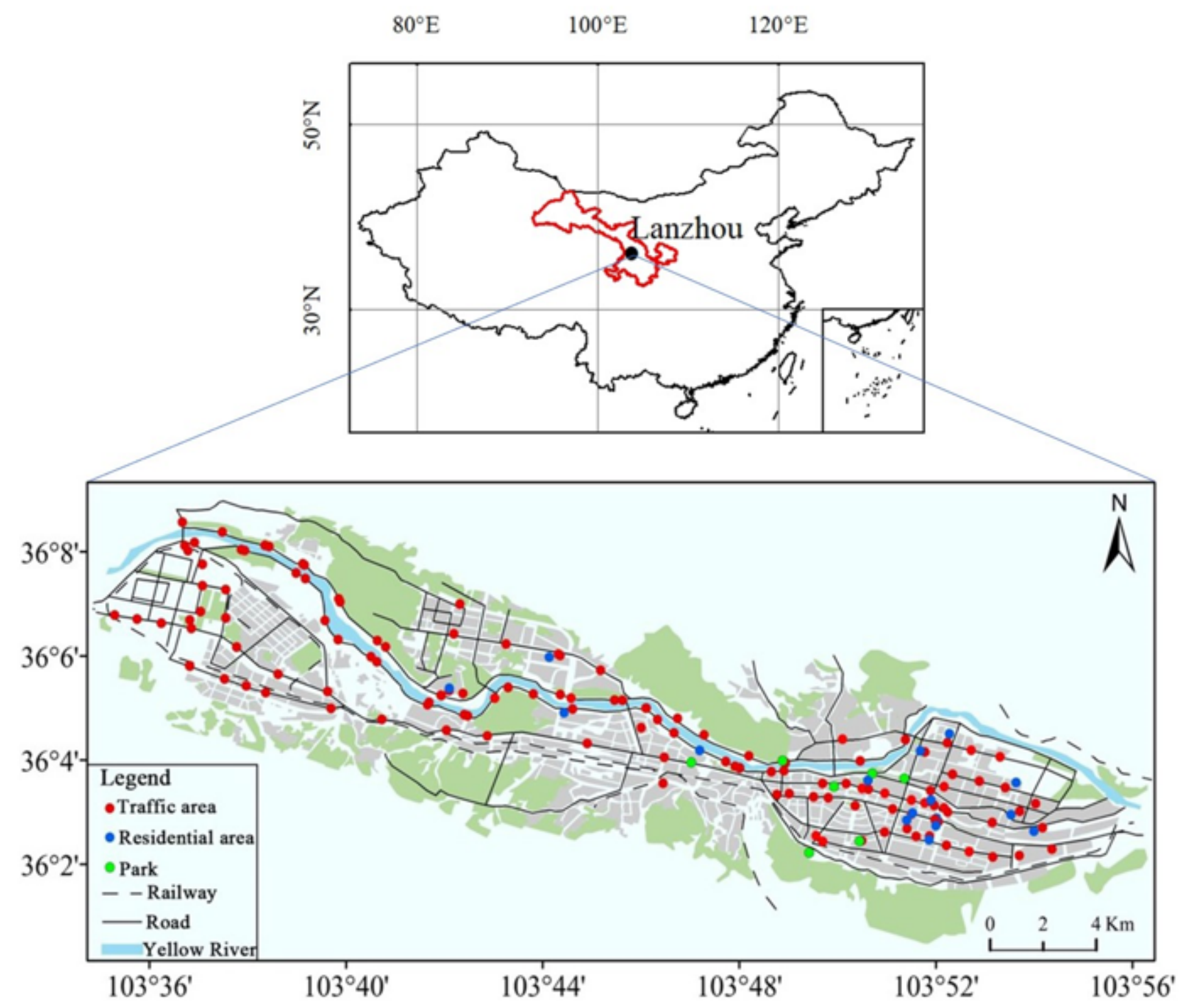

Figure 1

The study area of Lanzhou city and sampling locations. The inset map shows the location of Lanzhou in China. The dots indicate the sampling points in the considered functional areas. Note: The designations 
employed and the presentation of the material on this map do not imply the expression of any opinion whatsoever on the part of Research Square concerning the legal status of any country, territory, city or area or of its authorities, or concerning the delimitation of its frontiers or boundaries. This map has been provided by the authors.

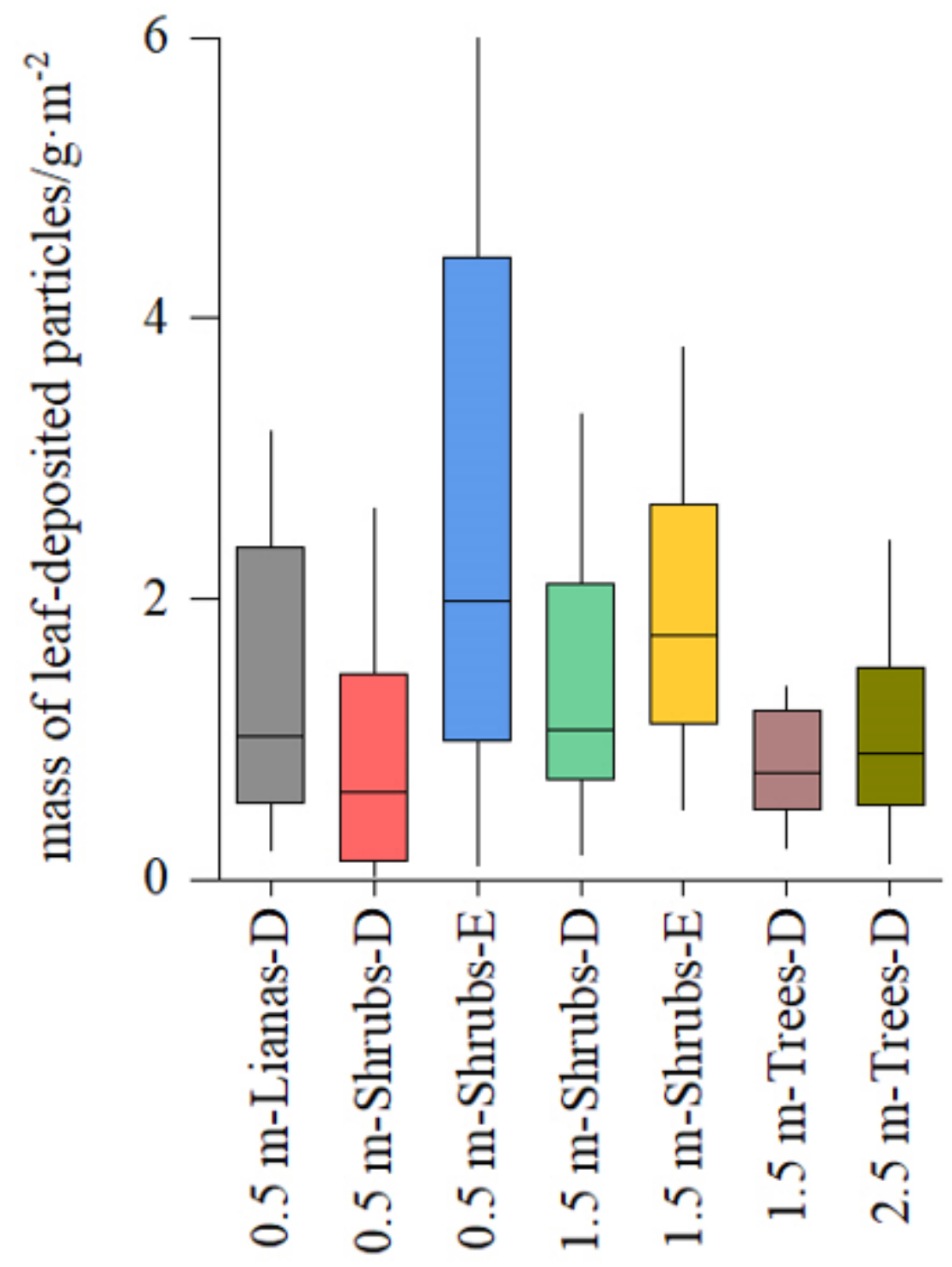

Figure 2

Box plots of the mass of leaf-deposited particles for different plant types $(n=7)$. D= Deciduous species $(n=361), E=$ Evergreen species $(n=240)$. The box indicates the first quartile while the top indicates the third quartile. The black lines indicate median values. 


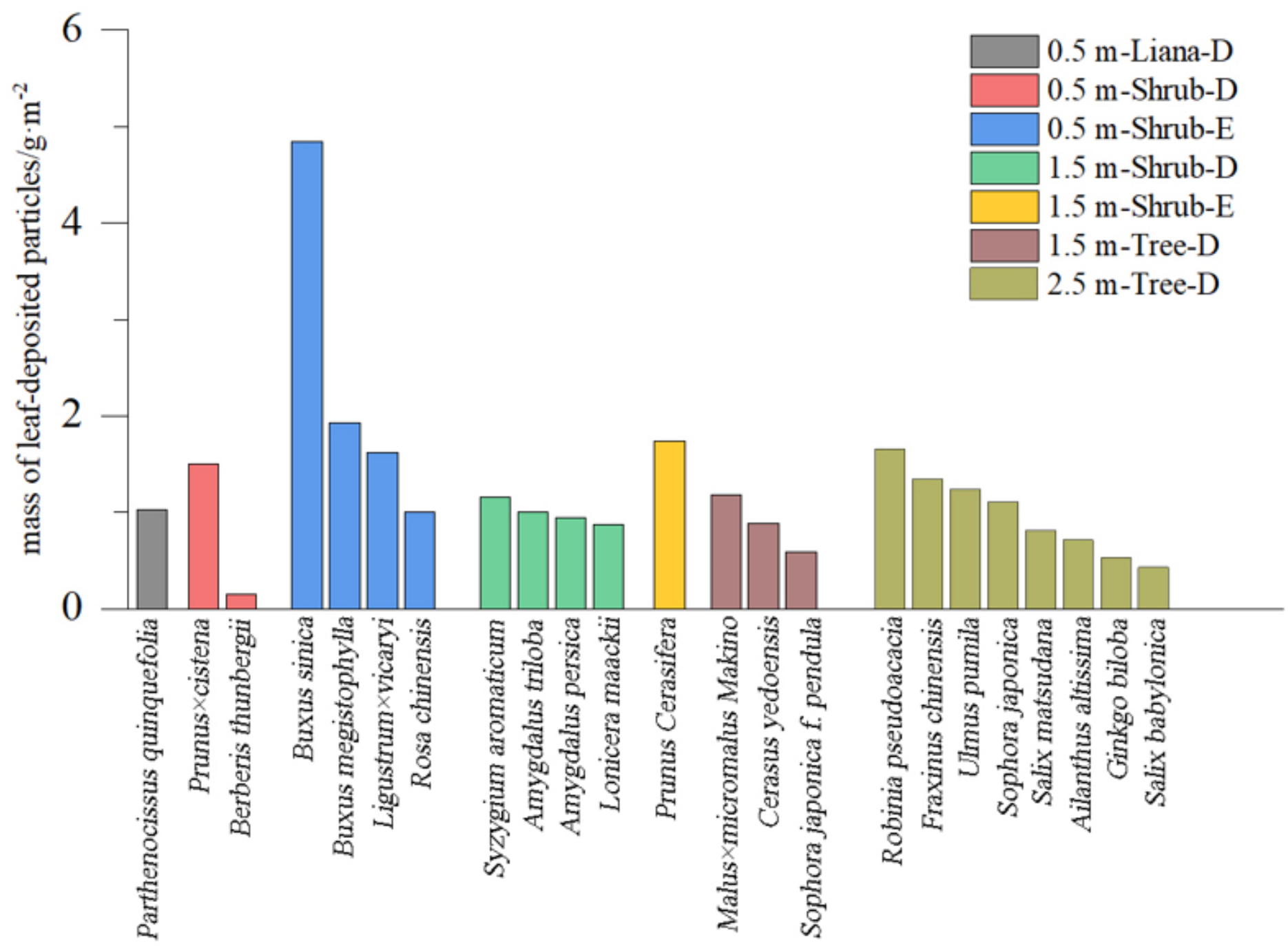

Figure 3

Median mass of leaf-deposited particles of the 23 plant species within 7 plant types $(n=601)$. $D=$ Deciduous ( $n=361), E=$ Evergreen $(n=240)$. 


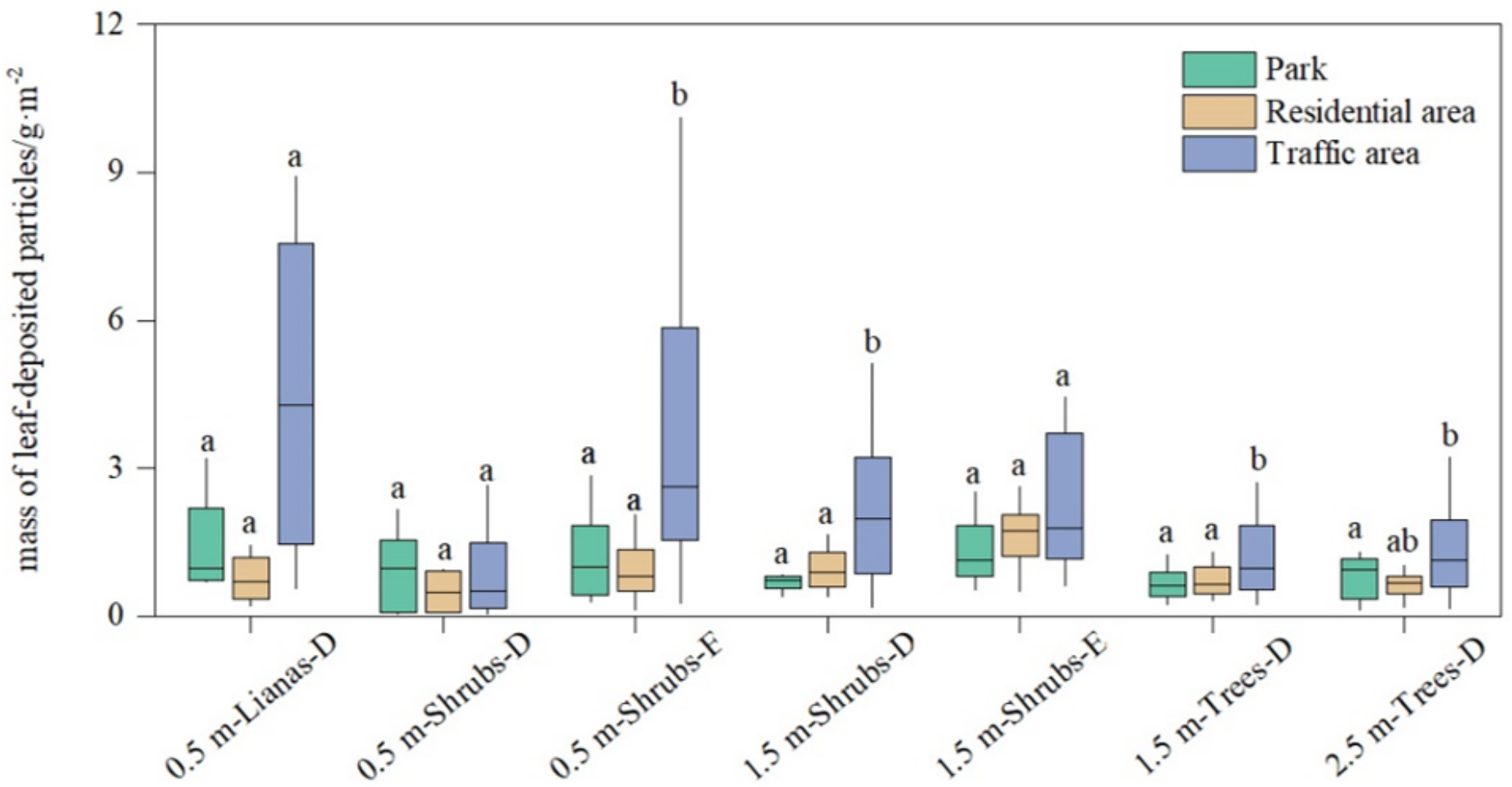

Figure 4

Box plots of the mass of leaf-deposited particles for the seven plant types ( $n=601)$ from traffic areas, parks and residential areas. $D=$ Deciduous $(n=361), E=$ Evergreen $(n=240)$. The same letter over the bar is not significantly different at $p<0.05$. The box indicates the first quartile while the top indicates the third quartile. The black lines indicate median values. 

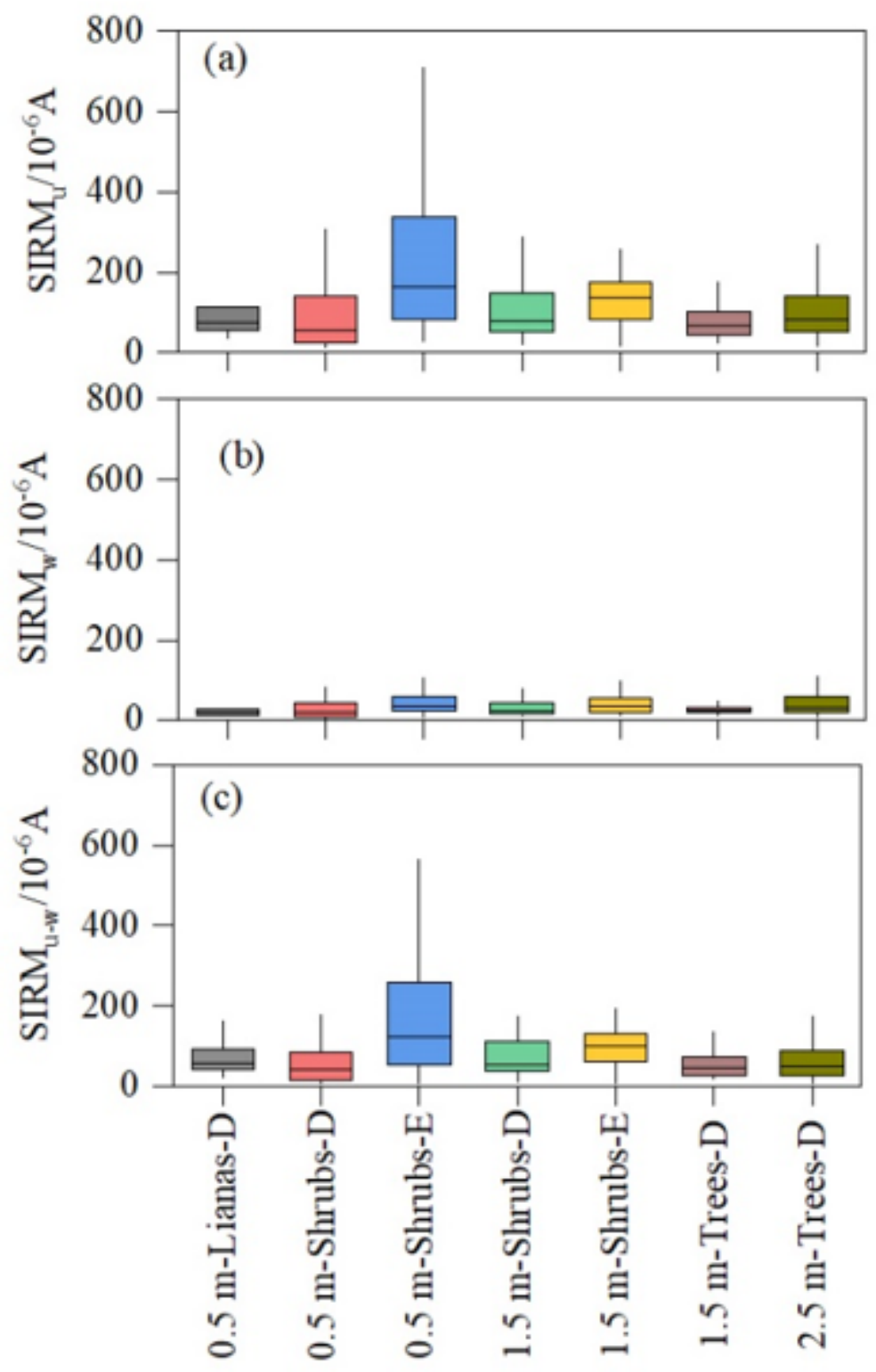

Figure 5

Box plots of SIRMu (a), SIRMw (b), SIRMu-w (c) for the different plant types. D = Deciduous $(n=361), E=$ Evergreen $(n=240)$. SIRMu = SIRM of unwashed plant leaves, SIRMw = SIRM of washed plant leaves, SIRMu-w $=$ the difference between SIRMu and SIRMw. The box indicates the first quartile while the top indicates the third quartile. The black lines indicate median values. 


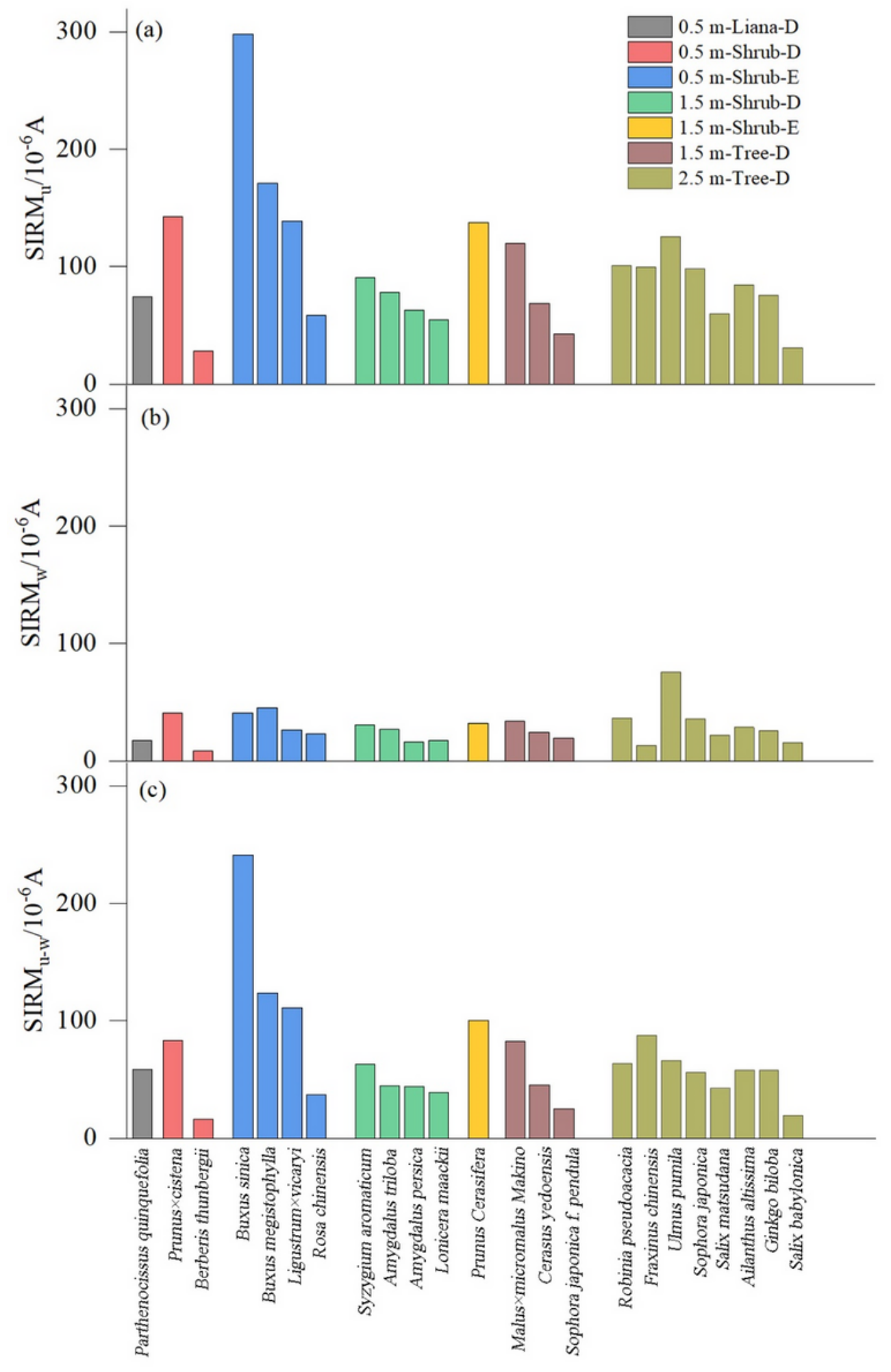

\section{Figure 6}

Median values of SIRMu (a), SIRMw (b), SIRMu-w (c) of the 23 investigated plant species within the seven considered plant species. $D=$ Deciduous $(n=361), E=$ Evergreen $(n=240)$. SIRMu $=$ SIRM of unwashed plant leaves, SIRMw = SIRM of washed plant leaves, SIRMu-w $=$ the difference between SIRMu and SIRMw. 


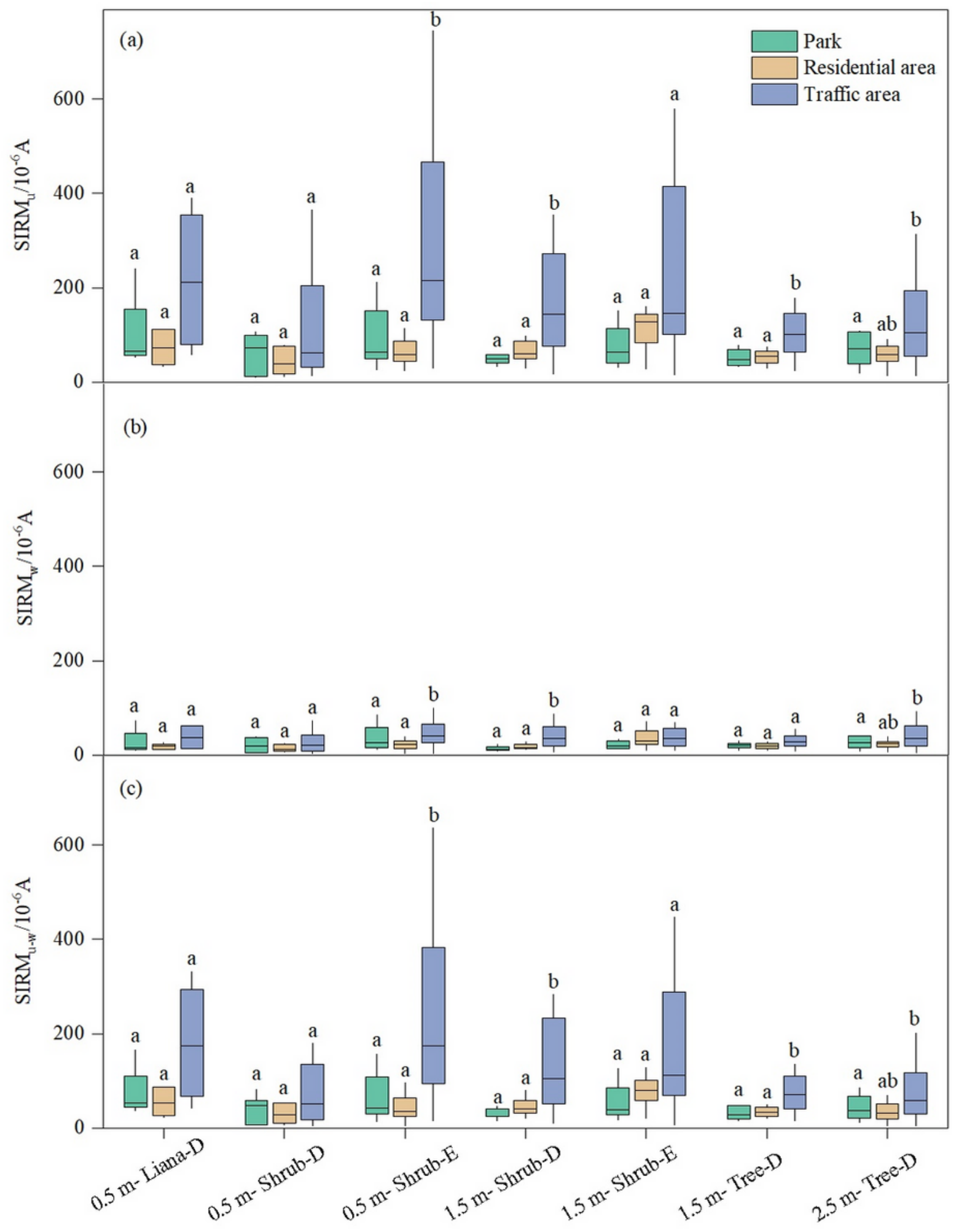

Figure 7

Box plots of SIRMu (a), SIRMw (b), SIRMu-w(c) for the seven considered plant types in parks, residential areas and traffic areas. $D=$ Deciduous $(n=361), E=$ Evergreen $(n=240)$.. SIRMu= SIRM of unwashed plant leaves, SIRMw = SIRM of washed plant leaves, SIRMu-w= the difference between SIRMu and SIRMw. The same letter over the bar is not significantly different at $p<0.05$. The box indicates the first quartile while the top indicates the third quartile. The black lines indicate median values. 

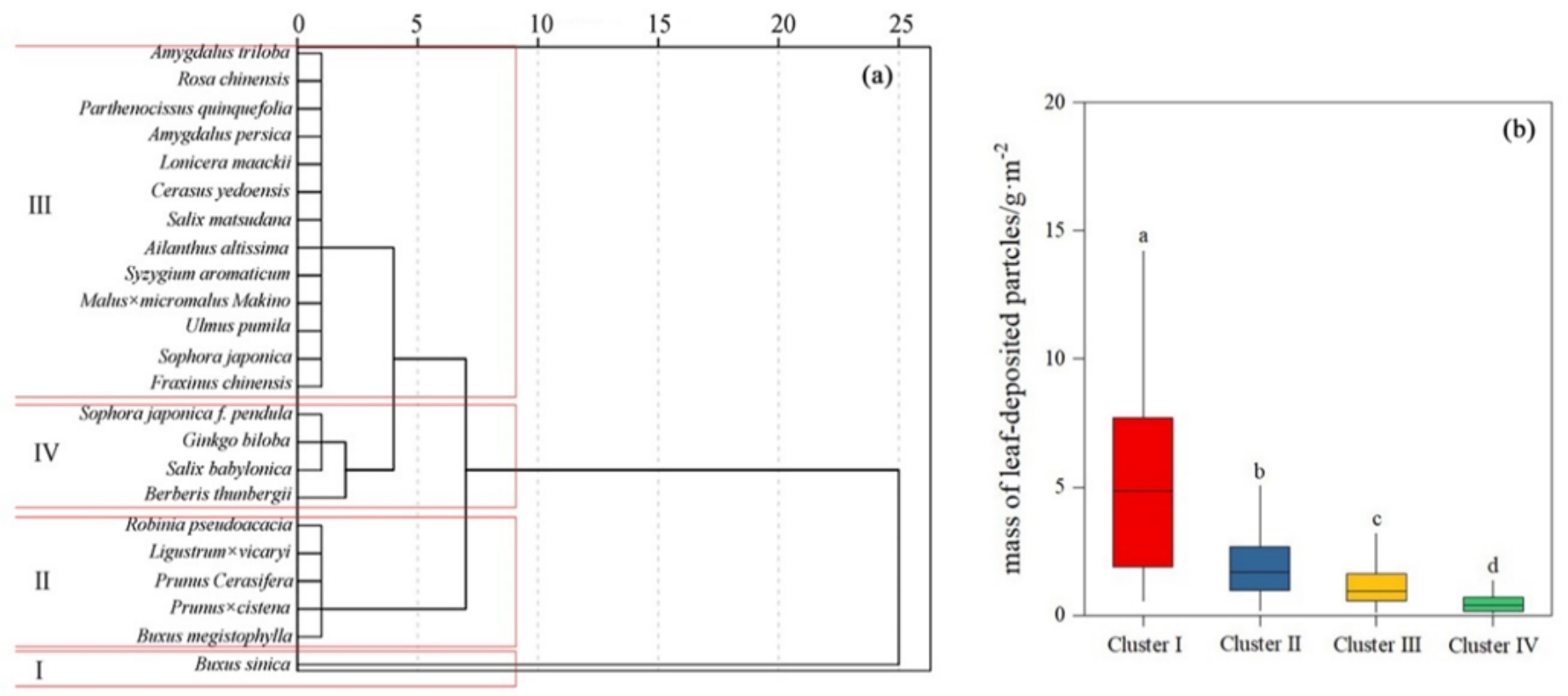

Figure 8

(a) Results of hierarchical cluster analysis of the mass of leaf-deposited particles (g.m-2) of 23 plant

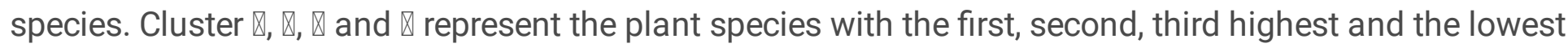
mass of leaf-deposited particles, respectively. (b) The mass of leaf-deposited particles of four clusters. The different letters over the box-plot are significantly different at $p<0.0001$. The box indicates the first quartile while the top indicates the third quartile. The black lines in the middle of the box indicate median values. 

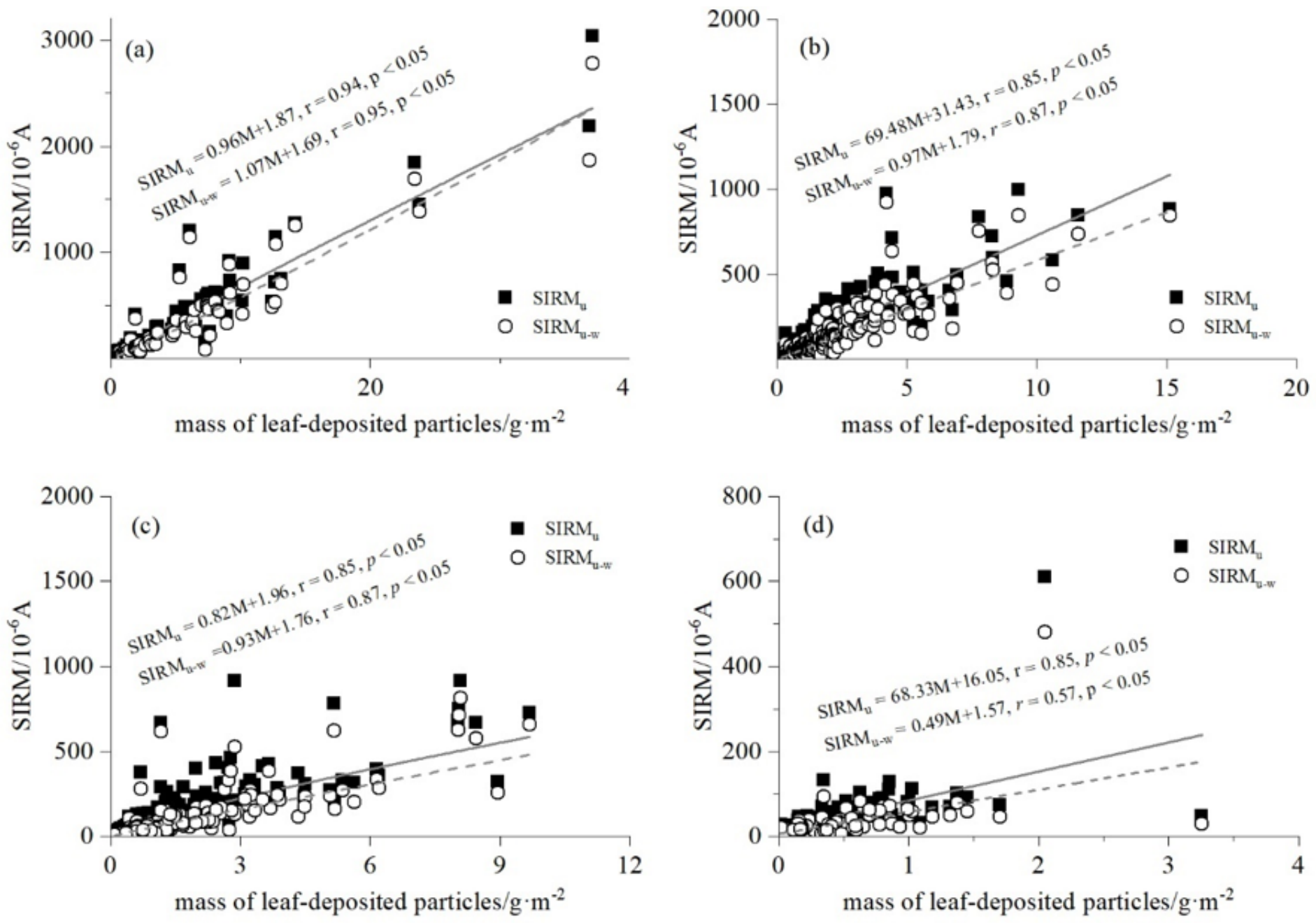

Figure 9

Scatter plots of the mass of leaf-deposited particles and SIRMu and SIRMu-w for the four clusters of plant species. SIRMu= SIRM of unwashed plant leaves, SIRMw= SIRM of washed plant leaves, SIRMu-w= the difference between SIRMu and SIRMw. (a) - (d) are cluster $\nabla-\otimes(n=70,194,250$ and 87), respectively. The solid lines represent linear regression lines fitted to all values, "solid" for SIRMu, "dashed" for SIRMuW.

\section{Supplementary Files}

This is a list of supplementary files associated with this preprint. Click to download.

- Supplementarymaterial.docx 